\title{
How to Treat Retrorectal Cysts or Tumors in Adult
}

\author{
Bong Hwa Lee, Hyoung Chul Park, Byung Seup Kim \\ Department of Surgery, Hallym University College of Medicine, Anyang, Korea
}

\section{See Article on Page 303-314}

Retrorectal or presacral tumors are rare and can be challenging to diagnose and treat. Because the retrorectal space contains multiple embryologic remnants derived from various tissues, the tumors that develop in this space are heterogeneous. Lesions are classified as congenital, neurogenic, osseous, inflammatory, or miscellaneous. The diagnosis is not difficult if one uses abdomenpelvis computed tomography and magnetic resonance imaging. The cases become difficult to treat when the patient has had a previous operation such as drainage of its content under the diagnosis of an anal fistula or sinus. Although treatment depends on diagnosis and anatomic location, most retrorectal lesions require surgical resection. Most lesions are benign, but malignant neoplasms are not uncommon. Thus, we should consider the bias in the article in terms of the retrorectal cyst being benign. When removal of the retrorectal mass is to be attempted, a frozen pathologic examination is mandatory.

Waldeyer's facia, which is a good landmark for surgery, divides the retrorectal space into inferior and superior compartments. There are no nerves, blood vessels or lymphatics within two leaves.

The operative approach is determined on digital examination and radiologic findings. When the examiner's finger cannot palpate the upper edge of the tumor, removing the cyst by only using a posterior approach is difficult. Levator muscles should be closed with sutures in cases of posterior approaches.

\section{REFERENCES}

1. Hobson KG, Ghaemmaghami V, Roe JP, Goodnight JE, Khatri
VP. Tumors of the retrorectal space. Dis Colon Rectum 2005;48: 1964-74.

2. Kye BH, Kim HJ, Cho HM, Chin HM, Kim JG. Clinicopathological features of retrorectal tumors in adults: 9 years of experience in a single institution. J Korean Surg Soc 2011;81:122-7.

3. Lee BH, Park HC, Lee HW, An CN, Um T, Lim YA, et al. Transsacral local resection as a posterior approach. J Korean Soc Coloproctol 2010;26:197-203.
Correspondence to: Bong Hwa Lee, M.D.

Department of Surgery, Hallym University College of Medicine, 896

Pyeongchon-dong, Anyang 431-070, Korea

Tel: +82-31-380-3772, Fax: +82-31-380-4118

E-mail: bshlee@hallym.ac.kr

(C) 2011 The Korean Society of Coloproctology

This is an open-access article distributed under the terms of the Creative Commons Attribution NonCommercial License (http://creativecommons.org/licenses/by-nc/3.0) which permits unrestricted noncommercial use, distribution, and reproduction in any medium, provided the original work is properly cited. 